\title{
Incidental bycatch mortality and fishing restrictions: impacts on juvenile survival in the Endangered Saimaa ringed seal Pusa hispida saimensis
}

\author{
Pekka Jounela ${ }^{1, *}$, Tero Sipilä $^{2}$, Jouni Koskela ${ }^{2}$, Raisa Tiilikainen$^{2}$, Miina Auttila $^{2}$, \\ Marja Niemi ${ }^{3}$, Mervi Kunnasranta ${ }^{3,4}$ \\ ${ }^{1}$ Natural Resources Institute Finland, 20520 Turku, Finland \\ ${ }^{2}$ Metsähallitus, Parks \& Wildlife Finland, 57130 Savonlinna, Finland \\ ${ }^{3}$ University of Eastern Finland, Department of Environmental and Biological Sciences, 80101 Joensuu, Finland \\ ${ }^{4}$ Natural Resources Institute Finland, 80110 Joensuu, Finland
}

\begin{abstract}
Incidental bycatch, mostly in gillnets used for recreational fishing, is a critical mortality factor for the Endangered Saimaa ringed seal Pusa hispida saimensis. Bycatch particularly affects juveniles, and therefore fishing has been restricted by banning gillnets during the most critical juvenile dispersal period in spring. In addition, the most harmful gear types for ringed seals of all ages are forbidden year-round. The springtime restriction areas have increased significantly since the 1990s, now covering over $90 \%$ of the pups' birth sites. However, the impacts of fishing restrictions on incidental bycatch mortality have not previously been evaluated statistically. The present estimates of incidental bycatch levels in relation to fishing restrictions since the 1990s suggest that the springtime gillnet fishing ban resulted in an increase in population size by $20 \%$ between 1991 and 2013 (60 individuals given an average estimated stock size of 355 in 2013). In addition, the estimated critical period for juvenile survival in relation to fishing operations appeared to be the first $15 \mathrm{mo}$, which is a much longer time than previously expected, suggesting that stationary gillnet fishing during late winter months may cause a secondary peak in seal mortality. One unwanted estimated side effect of the seasonal ban was a slightly increased incidental estimated bycatch level immediately after the end of the springtime fishing restriction period. The estimated bycatch peaked in 2000-2005, with an average of 13.3 juveniles annually and decreased thereafter, mainly in 2009-2013, with an average of 6.3 juveniles annually.
\end{abstract}

KEY WORDS: Entanglement $\cdot$ Gillnets $\cdot$ Machine learning $\cdot$ Mortality rate $\cdot$ Pinnipeds

\section{INTRODUCTION}

Fisheries incidental bycatch poses a significant threat to many marine mammal populations, especially with the use of passive gear, such as gillnets, which have contributed to the population declines of several species (Reeves et al. 2013). Additionally, the Endangered (Sipilä 2016) land-locked Saimaa ringed

\footnotetext{
*Corresponding author: pekka.jounela@luke.fi
}

seal Pusa hispida saimensis is threatened by various human-induced risk factors, among which incidental bycatch, together with climate change, may be regarded as the most critical sources of current mortality (Kovacs et al. 2012, Niemi et al. 2012, 2013, Auttila et al. 2014, Valtonen et al. 2014, Lyytikäinen et al. 2015, Kunnasranta et al. 2016, Liukkonen et al. 2017, 2018). In particular, juveniles are vulnerable to

() The authors 2019. Open Access under Creative Commons by Attribution Licence. Use, distribution and reproduction are unrestricted. Authors and original publication must be credited. 
bycatch mortality caused mostly by gillnets used in recreational fishing. Various fishing restrictions are enforced in Lake Saimaa: annual gillnet fishing prohibitions are applied during the most critical dispersal period (15 April-30 June) to improve the survival of the juveniles as they disperse, in addition to which the most harmful gear types for seals of all ages (fishbaited hooks, large fish traps with closed covers, wire basket fish traps with mouths wider than $150 \mathrm{~mm}$ and varied restrictions related to mesh size and line strength of gillnets) have been forbidden throughout the year since 1999 (Sipilä 2003). The patchy areas subject to the springtime gillnet fishing ban were gradually enlarged during 1991-2013, especially in the central breeding areas of the seals (Ministry of the Environment 2011). The conservation effects of this ban were evaluated by comparing proportions (relative sizes) of the banned fishing area with the breeding habitat. In 1991, the ban covered less than $20 \%$ of the seals' birth lair locations (Sipilä 2003), and it was assumed that by enforcing new protection areas, over $90 \%$ of the born pups would be protected by fishing restrictions (Ministry of the Environment 2011), although the areas of concern would still not cover all of the juvenile seals' potential dispersal patterns (Niemi et al. 2012, 2013).

Niemi et al. (2013) found that the home ranges of Saimaa ringed seal juveniles were much larger than had earlier been supposed, and they verified fishinginduced incidental deaths of $40 \%$ of the radio-tagged pups. This, and the combination of an increased number of pups being born but the size of the adult Saimaa ringed seal population remaining small, boosted a public debate on the magnitude and causes of unobserved deaths inside and outside the fishing restriction areas. Some stakeholders denied all unobserved deaths, while others suggested that the unobserved deaths were perhaps 3 times greater in number than the observed deaths (Ministry of the Environment 2011). Unfortunately, there are no other estimates of unobserved deaths than those presented by Niemi et al. (2013), and the causes of death of the additional observed stranded seals have remained unknown. A few dead, stranded seals are found both inside and outside the restriction areas each year, but it is rarely possible to diagnose the causes of those deaths because of the bad condition of the carcasses. In recent years, field observers have also verified a few incidental bycaught individuals within the banned areas, casting doubts on the real impact of fishing restrictions and the biological sustainability of the population in the face of such unquantifiable incidental bycatch.
In this work, we estimated the impact of fishing restrictions on incidental bycatch of Saimaa ringed seals using statistical methods. Our tools are purely statistical due to the absence of any concrete estimates for the main parameters required for such an assessment, such as causes of death, population size and biological sustainability. Instead, an array of machine learning techniques was used to compensate for these shortcomings, with their advantage being their ability to recognize patterns (of deaths) that are too obscure to be perceptible by human researchers employing standard statistical tools.

\section{MATERIALS AND METHODS}

\subsection{Data}

Lake Saimaa $\left(61^{\circ} 05-62^{\circ} 36^{\prime} \mathrm{N}, 27^{\circ} 15-30^{\circ} 00^{\prime} \mathrm{E}\right)$ is a freshwater basin that is approximately $180 \mathrm{~km}$ long and $140 \mathrm{~km}$ wide (Fig. 1); the area of interest in this study covers the current distribution of the Saimaa ringed seal (see Niemi et al. 2012). The mortality and birth lair data from 1991-2013 used in the analyses were obtained from the Saimaa ringed seal database of Metsähallitus Parks \& Wildlife Finland (2018). The mortality data, including cause, location, year and age, were based on 422 Saimaa ringed seal carcasses. Since no reliable time series exist regarding overall gillnet locations and fishing efforts, only the data based on the causes of seal mortality were used here. The causes of death were either determined by a wildlife pathologist or verified in the field (as in the case of bycatch in gillnets). The causes of death were classified as follows: (1) stillborn: pup dead at birth, (2) lair deaths: unweaned pups aged 0-2 mo, (3) fishing: bycaught seals aged $0-35 \mathrm{yr}$ and (4) others: weaned seals older than 2 mo that died of natural or unknown causes. The ages of the seals (excluding pups with lanugo hair) were determined by counting the cementum layers in the lower canine teeth (Stewart et al. 1996).

The birth rate data from 1991-2013 included the numbers of Saimaa ringed seals born in the years concerned $(\mathrm{N}=1104)$. Since ringed seals give birth to a single pup in a subnivean lair, the numbers of birth lairs can be used to estimate pup production (for details, see Sipilä et al. 1990, Sipilä 2003). Such data were collected during annual Saimaa ringed seal snow lair censuses conducted throughout the species' distribution area in late winter or early spring from 1991-2013. 


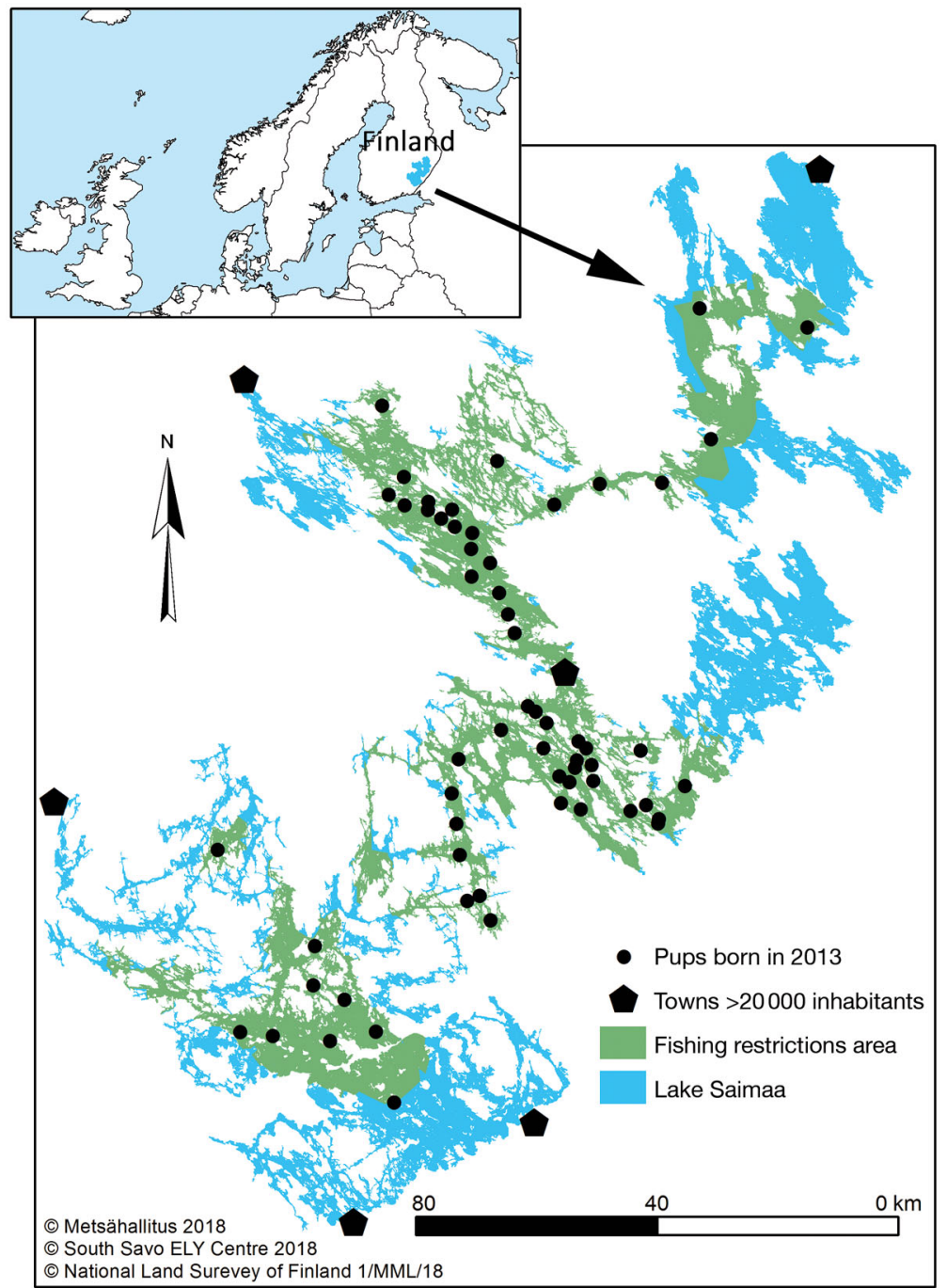

Fig. 1. Area of Lake Saimaa, Finland, inhabited by Saimaa ringed seals, with locations of their birth lairs (main breeding areas) and coverage of springtime fishing restrictions in 2013

\subsection{Statistical methods}

\subsubsection{Model structure}

Estimation of the total number of deaths began with the total number of annually born pups and ended when the survivors reached $30 \mathrm{yr}$ of age. There was only 1 very old seal (>25 yr, max. 35 yr). The estimation of the total number of deaths by cause of death in year $y$ is divided as follows: (1) estimation of the total mortality rate from age 0 to age $30 \mathrm{yr}$ in year $y$ and (2) estimation of the causes of death at given ages in year $y$. Incidental bycatch is assumed to occur only in areas without fishing restrictions, while other causes of death (stillborn, lair deaths, others) are assumed to occur both inside and outside the fishing restriction area.

\subsubsection{Causes of death estimation}

The causes of death patterns were estimated using a random forest (RF) model (Breiman 2001). RF consists of building an ensemble (forest) classifier of decision trees produced from bagging (bootstrap aggregated; see Breiman 1996) and a randomized variant of the tree induction algorithm. In ecological studies, RF has been applied for species distribution models (SDMs), e.g. for species conservation and biodiversity management purposes, and in the context of climate change (Guo et al. 2015). One general reason for using ensemble SDMs has been to reduce uncertainty and stability in predictions, especially when compared with a single SDM, such as a generalized linear model or a generalized additive model (Marmion et al. 2009a,b, Grenouillet et al. 2011, Guo et al. 2015). Dietterich (2000) identified statistical, computational and representational reasons, explaining why ensembles often work better than a single model. First, when the learning set is too small (as in our study), a learning algorithm can typically find several models (functions) in the hypothesis space and, by averaging several models, can reduce the risk of choosing the wrong hypothesis. Second, an ensemble made of individual models built from many different starting points may provide a better approximation of the true unknown function than one using any of the single models. By combining several models in an ensemble, it may be possible to expand the space of representable functions and obtain a better model of the true function. Consequently, among 179 classifiers arising from 17 families (discriminant analysis, Bayesian, neural networks, support vector machines, decision trees, rule-based classifiers, boosting, bagging, stacking, RFs and other ensembles, generalized linear models, nearest neighbours, partial least squares and principal component regression, logistic and multinomial regression, multiple adaptive regression splines and other methods), the best classifiers were different versions of RF (Fernandez-Delgado et al. 2014).

The predictors of cause of death distributions were latitude, longitude, seal age (in months) and year. The parameters of the RF model (specifically, number of trees: 10-1500; confidence level used for pes- 
simistic error calculation of pruning, i.e. removal of tree sections to improve predictive accuracy by the reduction of overfitting: $0.05-0.5$; maximal depth: $5-30$; and criterion for selecting attributes and numerical splits: accuracy, gain ratio, Gini index, information gain) were optimized using a sequential (repeated) grid search. That is, the optimization was repeated numerous times using different sub-ranges for the number of trees and tweaked using the remaining parameters until a plateau was found in the statistical performance (accuracy) beyond which more trees did not make any difference, and the performance score even showed a small dip.

The statistical performance of the RF model was evaluated using 10-fold cross-validation (Kohavi 1995), which means that the data were randomly split into $k$ (10) folds using stratified sampling, and each time $k-1$ folds were used for training and the remaining 1 fold for testing. The model with certain parameter values that tested best over the 10 nonoverlapping test folds was then selected. Finally, the best model with the best parameters was applied to all data. In general, the aim of 10 -fold cross-validation is to avoid over-fitting and to choose a model that is neither too simple nor too complex. It guards against testing hypotheses suggested by the data (called 'Type III errors') in cases where further samples are costly or impossible to collect. A model that is too simple usually has high bias and low variance, while a model that is too complex usually has low bias and high variance. That is, finding the best model amounts to making an appropriate trade-off between bias and variance, i.e. finding the best model follows the 'no free lunch' theorem (Wolpert \& Macready 1997).

\subsubsection{Mortality rate estimation}

The sample size of juvenile seals (aged 0-15 mo) was much higher (5-15 deaths annually) than that of the older adult seals ( $0-5$ deaths annually), so it was possible to estimate an annual mortality rate for the juveniles, but not for the older seals. The annual mortality patterns were recognized using a generalized regression neural network (GRNN; Specht 1991). First, the values of the predictors of mortality (age and year) were standardized between 0 and 1 . Then, $\log (\ln +1)$ transformed numbers (dead juveniles) in each age class (in months) in year $y$ were assessed. Finally, monthly mortality rates were estimated from the (negative) regression slope parameters of the GRNN regression estimate.

The mortality rate of the adult seals aged 1-30 yr was estimated using log-transformed age frequency distributions (also referred to as the 'catch curve' method; Hilborn \& Walters 1992). Initially, the number of seals in each age class was determined, and then the numbers were $\log (\ln +1)$ transformed; thereafter, total mortality was calculated as the negative slope of the regression. Finally, the error of the mortality estimates was calculated as the error of the slope of the regression.

In the adult mortality rate estimation, we used Bayesian linear regression with uninformative priors, i.e. we applied equal probability for each possible value of the prior mortality rate, which means that we did not assume any particular (unknown) mortality level a priori before performing the mortality analysis. Furthermore, we assumed a constant annual mortality rate for the adult seal age groups over the years because the annual sample size of adult seals was either 0 or extremely small ( $0-5$ annually).

\section{RESULTS}

\subsection{Incidental bycatch and the impacts of fishing restriction areas}

The springtime (15 April-30 June) fishing restriction areas have increased significantly in size and coverage since they were established in 1982, and

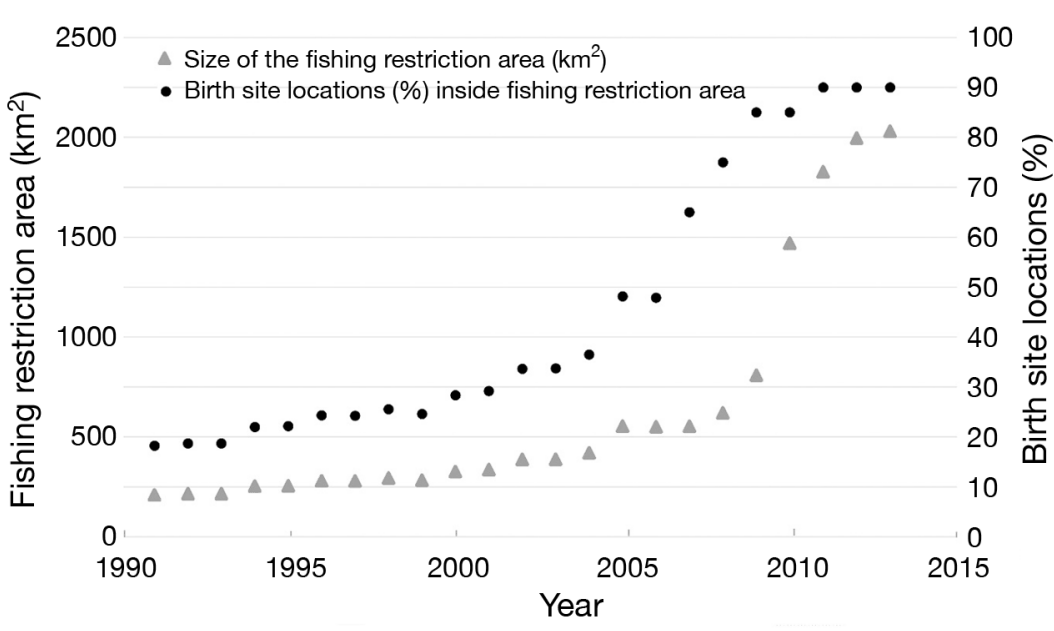

Fig. 2. Annual sizes of the springtime fishing restriction areas and estimated proportions (\%) of Saimaa ringed seal birth sites located within them in 1991-2013 
the increase has had an effect on juvenile survival. The areas covered $18 \%$ of the birth sites in 1991, whereas in 2013, the coverage was over $90 \%$ (Fig. 2). Although the first restrictions imposed to limit bycatch mortality were established as early as 1982 (Sipilä et al. 1990), systematic restrictions have been implemented on a larger scale (applying to both the season of the year and the gear type) only since 1999. In 2010, a major increase in the springtime total fishing restriction area was enforced in the main breeding areas of the seals, partly due to an increase in the distribution of the juveniles and of the ringed seal population in general (Fig. 2).

In 1991, the springtime fishing restriction areas had only a small positive influence on juvenile survival, whereas in 2013, the influence of the enlarged total restriction area was more significant (Fig. 3). However, an estimated side effect of the restriction areas in 2013 was a slight increase in estimated incidental bycatch levels after fishing began (on 1 July), when the juveniles were 4 mo old (Fig. 3). That is, a higher estimated number of survivors on 30 June led to a higher estimated incidental bycatch after fishing began on 1 July. The estimated bycatch peaked in 2000-2005, with an average of 13.3 juveniles annually, and was highest in 2004. The enlarged fishing restriction areas in 2010-2013 effectively reduced the bycatch of seals 0-4 mo old (Fig. 4).

The conservation impact of the springtime fishing restrictions increased significantly throughout the period concerned (Fig. 5). In the period 1991-2013, the annual impact of the restriction areas peaked at a juvenile age of 2.5-3 mo. The conservation impact of the fishing restriction areas in terms of the incidental bycatch was smaller at age 3.5 mo than at 2.5-3 mo, and was minimal at $0-$ 1 mo (Fig. 5).

If the springtime fishing restriction areas covered all of the ringed seals' birth sites throughout the period concerned, it is estimated that the number of juveniles surviving as a result of fishing restriction areas would have increased to an average of $\sim 7.8$ in- dividuals annually (average slope parameter, Fig. 6) compared to a situation with no restriction areas at all. As the restriction coverage was less than $100 \%$ (Fig. 2), only an average of 2.1 juveniles were estimated to have been saved annually by this management measure.

During 1990-1995, the estimated average annual bycatch of juveniles (0-15 mo old) was 7.9 (range 6.4-10.6) individuals, and during 2009-2013, it was 6.3 (range 4.4-8) individuals. The estimated number of seals incidentally bycaught during 2009-2013 was approximately half of that in the early 2000s. How-

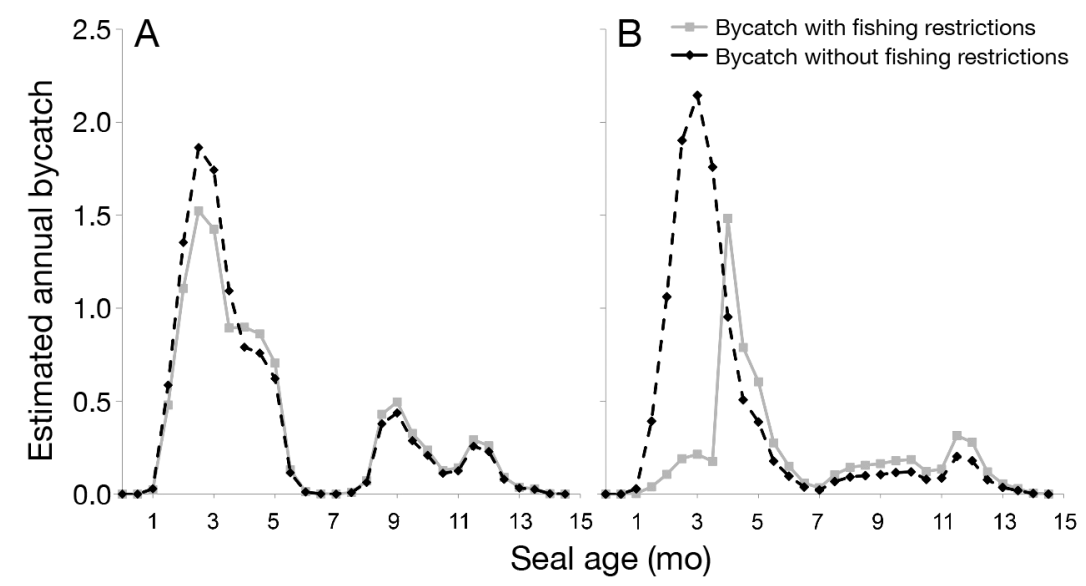

Fig. 3. Estimated annual instantaneous bycatch of Saimaa ringed seals (individuals) with and without fishing restriction areas in (A) 1991 and (B) 2013. When fishing began in 2013, i.e. when the juvenile seals were 4 mo old, the grey line is higher than the black dotted line, indicating a slightly increased bycatch

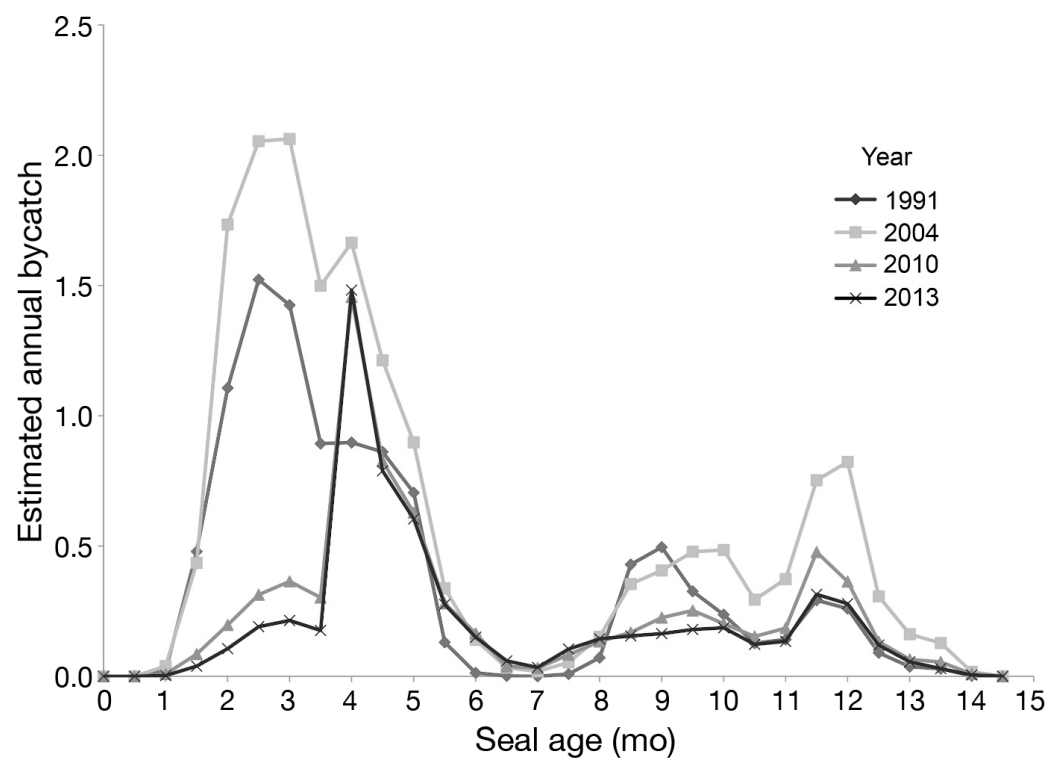

Fig. 4. Estimated bycatch of juvenile Saimaa ringed seals aged 0-15 mo in 1991, 2004, 2010 and 2013. Note the peak in 2004, after which the enlarged fishing restriction areas effectively reduced the bycatch of seals aged 0-4 mo 


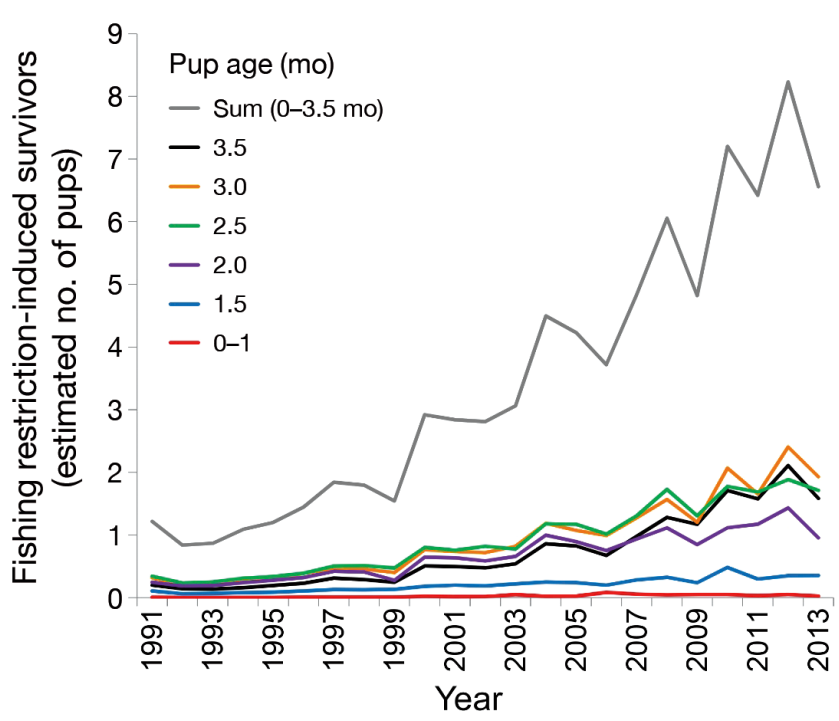

Fig. 5. Estimated instantaneous springtime fishing restriction-induced Saimaa ringed seal survivors (average number of individuals) at given ages (in months) in 1991-2013. The number of survivors peaked in 2012. The impact of the fishing restrictions on the survival of the juveniles started to increase at the age of $1.5 \mathrm{mo}$

ever, the observed bycatch mortality does not show the same pattern as the estimated mortality, as it has remained at approximately the same level throughout the interval 1991-2013 (Fig. 7).

\subsection{Population size}

The fishing restriction areas induced an increase in the population of the Saimaa ringed seal. The cumu-

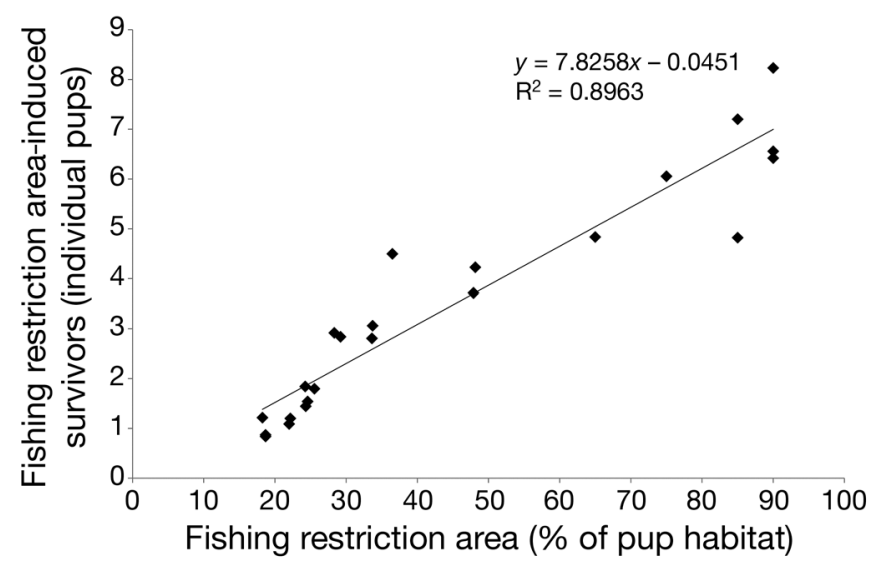

Fig. 6. Springtime fishing restriction-induced Saimaa ringed seal survivors (aged 0-4 mo) in relation to the coverage of birth sites (\%) in 1991-2013. The regression slope parameter (7.8258) suggests that $100 \%$ restriction coverage vs. $0 \%$ coverage could potentially increase the number of survivors by $\sim 7.8$ individuals (average annual estimate) lative increasing effect of the springtime fishing restrictions on the population size of the Saimaa ringed seal during 1991-2013 was 47 juveniles + 13 adults $(20 \%$ increase in population size from 295 seals in 1991 to 355 seals in 2013, Fig. 8). The estimated population size is an uncertain parameter that varies between 2 extremes, the estimated minimum and maximum distributions (Fig. 9).

\section{DISCUSSION}

Our results show the effectiveness of the enlarged springtime fishing restriction areas in reducing bycatch numbers of Saimaa ringed seal juveniles. Our analyses show that the estimated bycatch numbers in recent years were approximately half those in the early 2000s, whereas the observed bycatch numbers of juveniles (Fig. 7) remained approximately the same, and it appears that the restrictions did not have any impact on the survival of juveniles. However, it is also the unobserved (not reported, i.e. estimated minus observed, Fig. 7) bycatch numbers that have decreased in recent years. This shows the effectiveness of restrictions in safeguarding juveniles (Fig. 5), which nearly doubled the population size (seal numbers before birth) during 1991-2013. It can be expected that without the restrictions, the incidental bycatch in recent years would have been approximately double. Similarly, implementation of the fishing restrictions in 1991-2013 over an area covering all of the birth sites could potentially have increased juvenile survival, with an average of $\sim 7.8$ individuals estimated to have been saved annually. In practice, however, the reserve coverage was moderate, and therefore the population of 355 seals at the end of the period studied here included an estimated 60 individuals more than there would have been without the fishing restrictions (295 seals, Fig. 9).

Our results confirm earlier observations of the most critical period for juvenile survival (Sipilä 2003, Ministry of the Environment 2011, Niemi et al. 2013, Auttila et al. 2014) and show that the impact of fishing restrictions on juvenile survival begins at the age of $1.5 \mathrm{mo}$ and is less marked at age 3.5 mo than at 2.5$3 \mathrm{mo}$, which roughly corresponds to the time interval 15 May-15 July. However, the data also indicate that the estimated critical period for juvenile survival, as far as fishing practices are concerned, extends over the first $15 \mathrm{mo}$, as seen in the secondary peak in annual bycatch mortality after the end of the springtime fishing restriction period. Our analyses clearly point to this secondary peak in mortality and show 


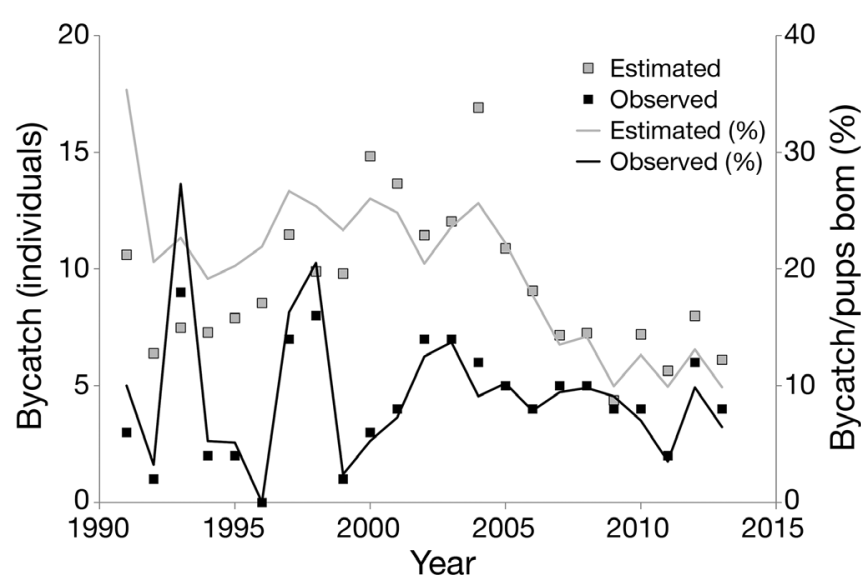

Fig. 7. Observed and estimated bycatch mortality of juvenile Saimaa ringed seals at age 0-15 mo. Observed and estimated bycaught individuals and their proportions (\%) of pups born annually in 1991-2013

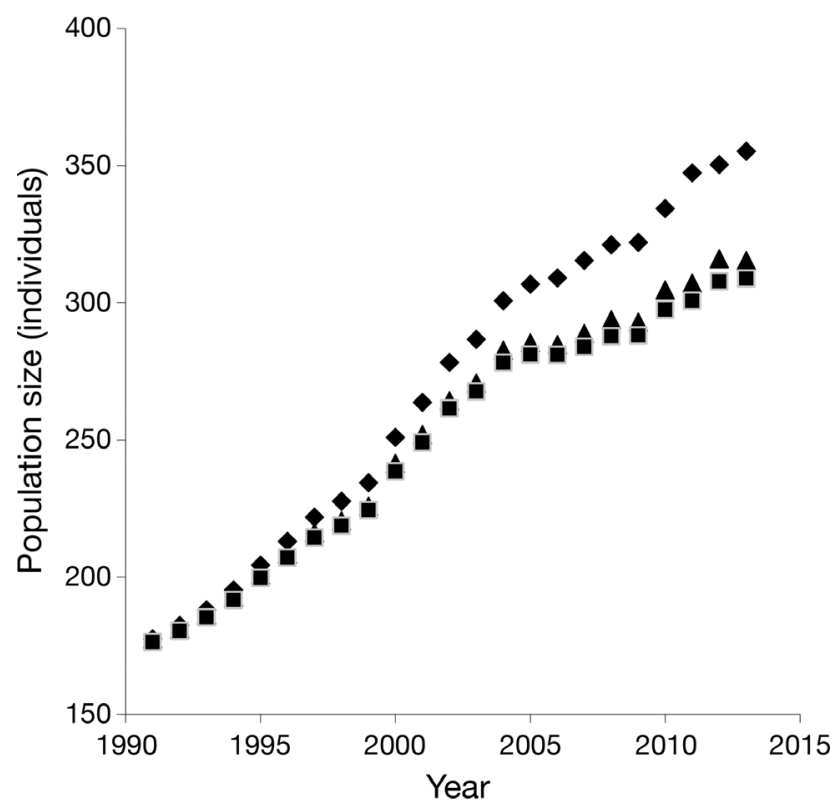

Fig. 8. Estimated average Saimaa ringed seal population sizes in 1991-2013, with cumulative fishing restriction impacts $(\bullet)$, with non-cumulative (single-year) restriction effects $(\boldsymbol{\Delta})$ and with no fishing restriction impacts $(\boldsymbol{\square})$

that the estimated bycatch peaked in 2004 and decreased thereafter over the interval 2009-2013 to an average of 6.3 individuals annually. Our estimates are also supported by recent records, which indicate increased bycatch mortality during that time (Metsähallitus Parks and Wildlife Finland 2018). This second mortality peak is typically caused by gillnet fishing during the autumn and winter. Although our results indicate relatively low bycatch numbers at the end of the period concerned (2009-2013, see Fig. 7), this could be an underestimate due to noise or concept drift (a change in statistical properties of the tar-

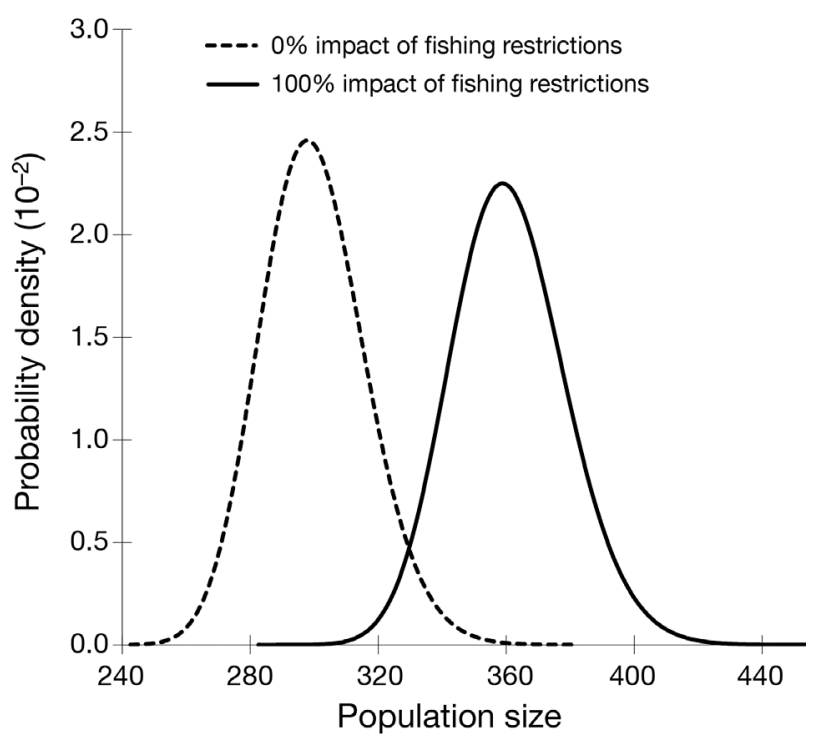

Fig. 9. Two estimated Saimaa ringed seal population size probability distributions in 2013, with 2 uncertain impacts of the fishing restriction areas. The maximum distribution (black solid line) assumes removal of all (observed and hidden) incidental bycatch within the fishing restriction areas in all years, and the minimum distribution (black dashed line) assumes that the fishing restriction areas had a zero impact on fishing bycatch inside fishing restriction areas

get variable). Some algorithms may overreact to noise, erroneously interpreting it as concept drift, while others may be highly robust with regard to noise, adjusting to the changes too slowly (Tsymbal 2004). The potentially elevated bycatch numbers have also been observed in mortality statistics in recent years (Metsähallitus Parks and Wildlife Finland 2018).

This is the first study to show the hidden bycatch mortality (see Fig. 7) in the Saimaa ringed seal population, as speculated earlier (Sipilä 2003, Ministry of the Environment 2011). One of the main assumptions here is that the cause of death assessment assumes that the probability of reporting is equal between all causes, which may not hold true. In July, for example, there are numerous people present (summer cottage owners and recreational fishermen) who are likely to report incidental bycatch deaths more often than in winter, when the harsh conditions attract fewer fishermen. However, the number of nets can also be considerable during that time because gillnet fishing in Lake Saimaa is focussed especially on the pike perch Sander lucioperca, which is one of the most valuable species both commercially and recreationally. In addition, the willingness to report incidental bycatch deaths may vary between seasons, and hence the estimated incidental bycatch patterns presented here 
should be considered 'best-guess' estimates (approximations) of the incidental bycatch mortality. There has also been debate about the acceptability of fishing restrictions to local people (Ratamäki \& Salmi 2015), which may also have caused the willingness of fishermen to report incidental bycatch to vary between the years over the whole period 1991-2013. The results and trends of the present study, however, do not significantly deviate from those reported earlier, and hence, the overall reliability of the assessment was considered plausible.

The nationally accepted biological reference point for the size of the Saimaa ringed seal population is that it should reach 400 adult seals by 2025 (Ministry of the Environment 2011). This has been officially defined as an 'intermediate goal' and would be achieved by allowing the population to grow by approximately $3-4 \% \mathrm{yr}^{-1}$. This reference point integrates the knowledge and opinions of various stakeholder groups, but it remains an open question as to which computational reference point method would be most appropriate for the Saimaa ringed seal. Consequently, there have been difficulties in justifying the maintenance of reasonably conservative fishing restrictions that both protect the Saimaa ringed seals and enable local small-scale subsistence fishing (Ratamäki \& Salmi 2015). In addition, along with incidental bycatch mortality, an increasing threat to population recovery from the mid-2000s onward has been the high perinatal mortality caused by the lack of adequate snow cover during the breeding season in February-March (Auttila et al. 2014). Additionally, a slightly less acknowledged but potentially severe threat has been the rapid increase in the number of summer cottages and associated activities, which has steadily reduced the potential breeding grounds along the shores of the Saimaa lake system (Liukkonen et al. 2017). Coping with these threats may prove to be a relatively complicated matter. Nevertheless, the findings presented here do show that reducing incidental bycatch mortality by extending the fishing restrictions has had substantial long-term effects on the growth rate of the Endangered Saimaa ringed seal population.

Juvenile survival of the Saimaa ringed seal is a critical element for successful conservation. Perinatal mortality typically varies between 10 and $20 \%$ (Auttila 2015), and after weaning, bycatch is the dominant mortality factor for juveniles (Kokko et al. 1999, Sipilä 2003, Niemi et al. 2013). In the future, perinatal mortality is likely to increase due to human disturbance (Liukkonen et al. 2017) and changing climate (Auttila 2015); therefore, mitigation of bycatch, a most acute mortality factor, is highlighted in conservation strategies, and fishing closures have been established. However, to be effective, fishing restrictions should be prolonged at least to the end of July to reduce the bycatch mortality peak in summer. In addition, our results on hidden mortality indicate that the observance of fishing regulations still requires both education and patrolling.

Acknowledgements. We thank Marja Isomursu of the Finnish Food Safety Authority for performing the seal carcass necropsies. This work was funded by the EU Life + Safeguarding Saimaa ringed seal project LIFE12NAT/FI/000367.

\section{LITERATURE CITED}

Auttila M (2015) The endangered Saimaa ringed seal in a changing climate-challenges for conservation and monitoring. PhD dissertation, University of Eastern Finland, Joensuu

Auttila M, Niemi M, Skrzypczak T, Viljanen M, Kunnasranta M (2014) Estimating and mitigating perinatal mortality of the endangered Saimaa ringed seal (Phoca hispida saimensis) in a changing climate. Ann Zool Fenn 51: $526-534$

Breiman L (1996) Bagging predictors. Mach Learn 24: 123-140

Breiman L (2001) Random forests. Mach Learn 45:5-32

Dietterich TG (2000) Ensemble methods in machine learning. In: Multiple classifier systems. MCS 2000. Lecture Notes in Computer Science, Vol 1857. Springer, Berlin, p 1-15

Fernandez-Delgado M, Cernadas E, Barro S, Amorim D (2014) Do we need hundreds of classifiers to solve real world classification problems? J Mach Learn Res 15: 3133-3181

Grenouillet G, Buisson L, Casajus N, Lek S (2011) Ensemble modelling of species distribution: the effects of geographical and environmental ranges. Ecography 34:9-17

Guo C, Lek S, Ye S, Li W, Liu J, Li Z (2015) Uncertainty in ensemble modelling of large-scale species distribution: effects from species characteristics and model techniques. Ecol Model 306:67-75

Hilborn R, Walters CJ (1992) Quantitative fish stock assessment. Choice, dynamics and uncertainty. Chapman \& Hall, New York, NY

Kohavi R (1995) A study of cross-validation and bootstrap for accuracy estimation and model selection. In: Mellish CS (ed) Proceedings of the $14^{\text {th }}$ international joint conference on artificial intelligence, Montreal, Quebec. Morgan Kaufmann Publishers, San Mateo, CA, p 1137-1143

Kokko H, Helle E, Lindström J, Ranta E, Sipilä T, Courchamp F (1999) Backcasting population sizes of ringed and grey seals in the Baltic and Lake Saimaa during the 20th century. Ann Zool Fenn 36:65-73

Kovacs KM, Aguilar A, Aurioles D, Burkanov V and others (2012) Global threats to pinnipeds. Mar Mamm Sci 28: 414-436

Kunnasranta M, Niemi M, Auttila M (2016) Conservation biology of the Saimaa ringed seal: from research to actions. Suom Riista 62:71-82 (in Finnish with English summary) 
Liukkonen L, Rautio A, Sipilä T, Niemi M, Auttila M, Koskela J, Kunnasranta M (2017) Long-term effects of land use on perinatal mortality in the Endangered Saimaa ringed seal population. Endang Species Res 34: 283-291

Liukkonen L, Ayllón D, Kunnasranta M, Niemi M, NabeNielsen J, Grimm V, Nyman AM (2018) Modelling movements of Saimaa ringed seal using an individual-based approach. Ecol Model 368:321-335

Lyytikäinen M, Pätynen J, Hyvärinen H, Sipilä T, Kunnasranta M (2015) Mercury and selenium balance in endangered Saimaa ringed seal depend on age and sex. Environ Sci Technol 49:11808-11816

Marmion M, Parviainen M, Luoto M, Heikkinen RK, Thuiller W (2009a) Evaluation of consensus methods in predictive species distribution modelling. Divers Distrib 15:59-69

Marmion M, Luoto M, Heikkinen RK, Thuiller W (2009b) The performance of state-of-the-art modelling techniques depends on geographical distribution of species. Ecol Model 220:3512-3520

Metsähallitus Parks \& Wildlife Finland (2018) Hyljekanta 2018 (Saimaa ringed seal population). www.metsa.fi/ saimaanorppa/hyljekanta2018 (in Finnish; accessed 8 March 2018)

Ministry of the Environment (2011) A conservation strategy and action plan for the Saimaa ringed seal. Ympäristöministeriö, Helsinki (in Finnish)

Niemi M, Auttila M, Viljanen M, Kunnasranta M (2012) Movement data and their application for assessing the current distribution and conservation needs of the endangered Saimaa ringed seal. Endang Species Res 19: 99-108

Niemi M, Auttila M, Viljanen M, Kunnasranta M (2013) Home range, survival and dispersal of endangered Saimaa

Editorial responsibility: Rebecca Lewison, San Diego, California, USA ringed seal pups: implications for conservation. Mar Mamm Sci 29:1-13

Ratamäki O, Salmi P (2015) The most contested in Finland: large carnivores and the Saimaa ringed seal - challenges of socio-ecological rhythms and their practical implications. Eur Countrys 7:1-15

Keeves RR, McClellan K, Werner TB (2013) Marine mammal bycatch in gillnet and other entangling net fisheries, 1990 to 2011. Endang Species Res 20:71-97

Sipilä T (2003) Conservation biology of Saimaa ringed seal (Phoca hispida saimensis) with reference to other European seal populations. PhD dissertation, University of Helsinki

Sipilä T (2016) Pusa hispida ssp. saimensis. The IUCN Red List of Threatened Species 2016: e.T41675A66991678. http://dx.doi.org/10.2305/IUCN.UK.2016-1.RLTS.T41675 A66991678.en (accessed 7 February 2019)

Sipilä T, Helle E, Hyvärinen H (1990) Distribution, population size and reproductivity of the Saimaa ringed seal (Phoca hispida saimensis Nordq.) in Finland, 1980-84. Finn Game Res 47:3-10

Specht DF (1991) A generalized regression neural network. IEEE Trans Neural Netw 2:568-576

* Stewart REA, Stewart BE, Stirling I, Street E (1996) Counts of growth layer groups in cementum and dentine in ringed seals (Phoca hispida). Mar Mamm Sci 12:383-401

Tsymbal A (2004) The problem of concept drift: definitions and related work. Tech Rep TCD-CS-2004-15. Trinity College, Dublin

*Valtonen M, Palo JU, Aspi J, Ruokonen M, Kunnasranta M, Nyman T (2014) Causes and consequences of fine-scale population structure in a critically endangered freshwater seal. BMC Ecol 14:22

Wolpert DH, Macready WG (1997) No free lunch theorems for optimization. IEEE Trans Evol Comput 1:67-82

Submitted: April 25, 2018; Accepted: January 7, 2019 Proofs received from author(s): February 7, 2019 